\title{
Dynamic Load Models for Voltage Stability Studies with a Solution of UPFC using CSO
}

\author{
G Naveen Kumar \\ Assistant Professor \\ VNR VJIET, Hyderabad, India
}

\author{
M Surya Kalavathi, Ph.D. \\ Professor \\ JNTUH CEH, Hyderabad, India
}

\begin{abstract}
Efficient load models are essential and important for power system load modeling constraint voltage stability studies. Dynamic load models allow a more precise calculation of stability limits that are critical in the planning and operation of power systems. Voltage stability which defines ability of a power network to maintain steady voltages deals with many a kind of disturbance parameters. Variation in loads is considered one such category of disturbance which may result to instability. In this paper, we are trying to analyze modeling parameters of loads for voltage stability studies. We are performing a dynamic load modeling study. The accuracy and correctness of the results are directly related to the load models used in this analysis. The method is analyzed using continuation power flow routine. FACTS technology with a combination of Cat Swarm Optimization heuristic approach is applied to give a solution for the problem of instability. The effectiveness of the proposed method is demonstrated through quantitative studies on standard IEEE 6 bus and 14 bus networks.
\end{abstract}

\section{Keywords}

Continuation Power Flow, Cat Swarm Optimization, Load Model, Unified Power Flow Controller, Voltage Stability.

\section{INTRODUCTION}

During the system disturbances and their impacts on other power system elements, system stability is imperiled and the probability of moving to the global instability increases. This will usually make a power system to break up in the isolated sub-systems known as islands and then a complete blackout results unless some precautions are considered. Voltage Stability also termed as Load Stability is one of the concerns in power systems which are heavily loaded, faulted or having a shortage of reactive power $[1,2]$. The problem of voltage stability concerns the whole power system, although it usually has a large involvement in one critical area of the power system. Example of the recent massive black out of India's power grid was the worst in the decade, where, three out of the five regional power grids collapsed leaving about 670 million people powerless making July 2012 as the largest blackout month in history. Firstly, the regional grid collapsed at about 2.35 am on 30th July, 2012 due to increased load and gird disturbance leaving nine states of Northern India powerless including Delhi, the capital of India. Nearly 350 million people suffered due to this power outage which resulted for about a day. Restoration work followed with major networks of Rails, Airports, Metro and other important areas being restored under the direction of CEO, POSOCO and POWER Grid's Chairman \& Managing Director as stated by Power Grid Corporation of India. But, within 24 hours of restoration work, again the Northern region grid collapsed for the second time on 31, July 2012 at around 1pm local time on Tuesday. This time the sudden power outage resulted in collapse of two more regional girds namely, the Eastern and the North-Eastern regional Grids which spread across 20 of India's 28 states leaving about 620 million people affected. Half of the India's states like Delhi, Bihar, Orissa, Punjab, Haryana, Rajasthan, Uttar Pradesh etc were facing blackout Tuesday with more problems like massive traffic jams due to failed traffic lights, miners being trapped underground as lifts failed, metro services coming to an halt and people were left scorching in the summer heat.

According to [13, 14] Power System Load Modeling is a technique used to model the power system and essential for stability assessments. In this paper, we are trying to analyze modeling parameter inputs to loads for voltage stability studies. We are performing dynamic load modeling and the accuracy and correctness of the results for voltage stability are directly related to the load models used in this analysis. Different load models would greatly affect voltage stability aspect of an interconnected power system. We are using continuation power flow to analyze the effects of different load models and compare the results. To analyze the maximum loading parameter and bus voltage magnitude profile aspects, we are modeling the power system with different types of loads.

Flexible Alternating Current Transmission Systems in short FACTS controllers are used to control the variables such as voltage magnitude and phase angle at chosen bus and line impedance where a voltage collapse is observed [3, 4]. Introducing FACTS devices is the most effective way for utilities to improve the voltage profile and voltage stability margin of the system. As the size and the cost of the FACTS devices are high, an optimal location and size has to be identified before they are actually installed $[8,9]$.

\section{PROBLEM DEFINITION AND OBJECTIVE FUNCTION}

Accurate modeling of loads continues to be a difficult task due to several factors, for example, lack of precise information on the composition of the load, changing of load composition with time delay and week, seasons, weather, through time and more. Electric utility analysts and their management require evidence of the benefits of improved load representation in order to justify the effort and expense of collecting and processing load data, as well as to modify computer program load models. The interest in load modeling has been continuously increasing in the last years, and power system load modeling has become a new research area in power systems stability. Several studies have shown the critical effect of load representation in voltage stability studies, and therefore the need of finding more accurate load models than the traditionally used ones. In this paper we are trying to test two dynamic load models for determining the voltage stability limits of a system namely Induction Motor loads and Thermostatically Controlled loads. FACTS controllers are employed to give a solution for instability margins. We are considering the problem case of Generator 
outage contingency while performing the above. We are trying to improve the voltage magnitude profile, maximum loading parameter using FACTS controllers. A solution is given to mitigate the harmful effects of voltage instability criterion on the power system using FACTS controllers via heuristic approach namely Cat Swarm Optimization.

The objective function for the above problem is defined as follows

$$
\mathrm{F}=\left\{\mathrm{F}_{1}, \mathrm{~F}_{2}, \mathrm{~F}_{3}\right\}
$$

The functions $\mathrm{F}_{1}, \mathrm{~F}_{2}$ and $\mathrm{F}_{3}$ are defined and used in optimization process.

$$
\mathrm{F}=\Phi_{1} \mathrm{~F}_{1}+\Phi_{2} \mathrm{~F}_{2}+\Phi_{3} \mathrm{~F}_{3}
$$

In our study, the fitness function is defined as a sum of three terms with individual criteria. The first part of the objective function concerns the voltage level. It is favorable that buses voltages be as close as possible to 1 p.u. Equation (3) shows the voltage deviation in all buses.

$$
\begin{gathered}
\mathrm{F}_{1}=\underset{\mathrm{i}}{\mathrm{F}_{\mathrm{v}}}=\left[\Sigma\left(\mathrm{V}_{\mathrm{i}}-1\right)^{2}\right]^{1 / 2} \\
\mathrm{i}=1
\end{gathered}
$$

Where $\mathrm{nb}$ is the number of buses and $\mathrm{Vi}$ is the voltage of bus i.

F2-This function represents the optimal location and size of UPFC which has its dependence on F1.This is related to having the minimum possible UPFC sizes regarding to the control of UPFC that is given by (4).

$$
\begin{gathered}
\mathrm{m} \\
\mathrm{F}_{2}=\mathrm{F}_{\mathrm{S}}=\alpha \Sigma \mathrm{Q}_{\mathrm{j}} \\
\mathrm{j}=1
\end{gathered}
$$

Where ' $\mathrm{m}$ ' is the number of UPFC and ' $\mathrm{Q}_{j}$ ' is the value of UPFC's Kvar and ' $\alpha$ ' is a weight in order that the terms in the fitness function are comparable in magnitude. Value of UPFC's Kvar considering the control strategy and UPFC's model is achieved. The maximum loadability of power system is extremely important and hence it is considered as the third part of the objective function. So, finally, the third issue in our problem is determining inverse of maximum loadability, given as follows:

$$
\mathrm{F}_{3}=\mathrm{F}_{\mathrm{SM}}=1 / \lambda_{\text {Critical }}
$$

Therefore, the objective function is given by the following equation.

$$
\mathrm{F}=\Phi_{1} \mathrm{~F}_{\mathrm{V}}+\Phi_{2} \mathrm{~F}_{\mathrm{S}}+\Phi_{3} \mathrm{~F}_{\mathrm{SM}}
$$

\section{CASE STUDIES AND SOFTWARE USED}

The testing procedures are performed on IEEE 14-bus system and IEEE 6-bus system. The specifications of IEEE 14 bus system can be given as: the number of buses being 14, the number of lines being 16, the generator count is 5 (including slack bus) and the number of load buses being 11 . The specifications of IEEE 6 bus system can be given as: the number of buses being 6 , the number of lines being 11 , the generator count is 2 and the number of load buses being 3 . Base MVA of 100 is assumed for both the case studies. All the analysis and testing is performed in MATLAB/SIMULINK [6]. Figure 1 shows the IEEE 6 bus network. Figure 2 shows the IEEE 14 bus network.

\section{CAT SWARM OPTIMIZATION AND FACTS \\ 4.1 Introduction to Cat Swarm Optimization}

Optimization techniques find a variety of use in many fields. The use of these techniques in power systems is playing an important role for the optimal location of FACTS devices. In the field of optimization, many algorithms were being proposed in the recent past. To name a few, Genetic Algorithm (GA), Ant Colony Optimization (ACO), Particle Swarm Optimization (PSO), Simulated Annealing (SA) etc. Some of these optimization algorithms were developed based on swarm intelligence. Cat Swarm Optimization in short CSO, the algorithm, is motivated from PSO and ACO. According to the literatures, PSO with weighting factor usually finds the better solution faster than the pure PSO, but according to the experimental results, Cat Swarm Optimization (CSO) presents even much better performance $[10,11]$. In Cat Swarm Optimization, we first model the behavior of cats into two sub-models, namely, seeking mode and tracing mode [12].

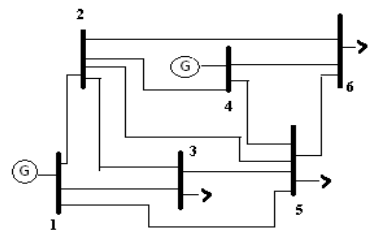

Fig 1: IEEE 6-bus system

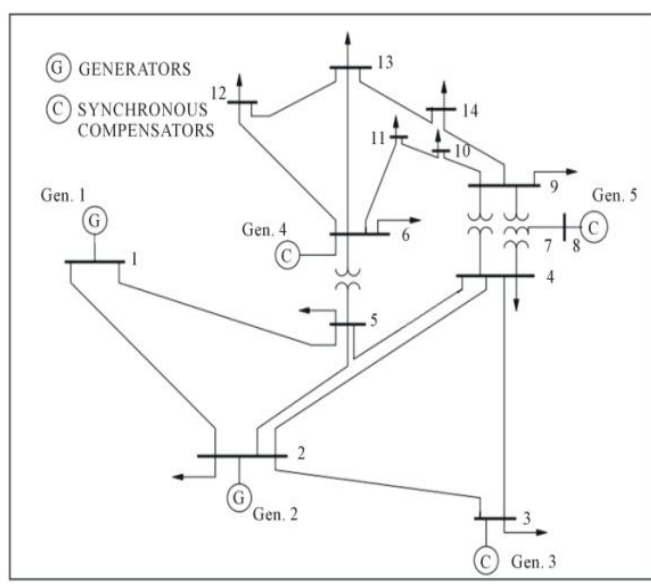

Fig 2: IEEE 14-bus system

\subsubsection{Seeking Mode}

This sub-model is used to model the situation of the cat, which is resting, looking around and seeking the next position to move to [12]. In seeking mode, we define four essential factors: seeking range of the selected dimension (SRD), counts of dimension to change (CDC), and self-position considering (SPC). SMP is used to define the size of seeking memory for each cat, which indicates the points sought by the cat.

The seeking mode can be described in 5 steps as follows:

Step1: Select the total number cats that have to be considered.

Step2: For each cat, a fixed range of velocities has to be assumed.

Step3: Calculate the fitness values of all candidate points.

Step4: Select how many cats to be available in seeking mode. 
Step5: Randomly pick the cat from the total number of cats and apply in seeking mode according to the equation (8)

$$
\mathrm{P}_{\mathrm{kn}}=\left[(1 \pm 0.3) \text { Rand ( ) } \mathrm{P}_{\mathrm{k}}\right.
$$

Where, $\mathrm{n}=1,2,3,4,5 \ldots$.

Where Rand ( ): is a random value in the range of $[0,1]$.

Here, ' $\mathrm{P}$ ' is the pick-up of the cat from a random number of cats and $\mathrm{P}_{\mathrm{k}}$ is the total number of cats available for application.

\subsubsection{Tracing Mode}

Tracing mode is the sub-model for modeling the case of the cat in tracing some targets. Once a cat goes into tracing mode, it moves according to its own velocities for every dimension [12]. The action of tracing mode can be described in 3 steps as follows:

Step1: Update the velocities for every dimension $\left(\mathrm{V}_{\mathrm{k}, \mathrm{d}}\right)$ according to equation.

Step2: Check if the velocities are in the range of maximum velocity. In case the new velocity is over range, set it be equal to the limit.

Step3: Update the position of $\mathrm{cat}_{\mathrm{k}}$ and again calculate the best fitness value. Proceed till the best fitness value is obtained and correspondingly, the cat location and the velocity.

$$
\mathrm{V}_{\mathrm{k}, \mathrm{d}}=\mathrm{V}_{\mathrm{k}, \mathrm{d}}+\mathrm{r}_{1} \cdot \mathrm{c}_{1} \cdot\left(\mathrm{P}_{\text {best }, \mathrm{d}}-\mathrm{P}_{\mathrm{k}, \mathrm{d}}\right), \mathrm{d}=1,2, \ldots, \mathrm{M}
$$

Where $\mathrm{P}_{\text {best,d }}$ is the position of the cat, which has the best fitness value.

$\mathrm{V}_{\mathrm{k}, \mathrm{d}}$ is the velocity for every dimension.

$P_{k, d}$ is the position of catk, $c_{1}$ is a constant and $r_{1}$ is a random value in the range of $[0,1]$.

The algorithmic flow routine for the CSO can be explained through the flow chart in figure 3 whose essence is captured from [11] and simplified

\subsection{Unified Power Flow Controller}

Flexible AC Transmission Systems (FACTS) are being used in power systems since 1970s with the objective of improving system dynamic performance [5]. Due to the environmental, right of way, and cost problems in both bundled and unbundled power systems, many transmission lines have been forced to operate at almost their full capacities worldwide. FACTS controllers enhance the static performance viz. increased loading, congestion management, reduced system loss, economic operation, etc., and dynamic performance viz. increased stability limits, damping of power system oscillation, etc. The concept of FACTS involves a family of fast acting, high power, and electronic devices, with advanced and reliable controls. In recent years, many different FACTS controllers have been proposed, performing a wide variety of functions. Using FACTS controllers one can control the variables such as voltage magnitude and phase angle at chosen bus and line impedance where a voltage collapse is observed. We are using Unified Power Flow Controller in our application.

The Unified Power Flow Controller in short, UPFC is a combination of STATCOM and SSSC, sharing a common dc link as shown in figure 3 . The UPFC can control both active and reactive power flow in the line. It provides independently controllable shunt reactive compensation. The UPFC is a two- port circuit (in series with a transmission line and parallel with a bus bar) [4]. The series voltage source and the shunt current source are defined as in [7].

$$
\begin{gathered}
V_{S}=\left(V_{p}+V_{q}\right) e_{j \varphi}=r V_{k} e_{j \gamma} \\
i_{S H}=\left(i_{p}+i_{q}\right) e j \theta_{k}
\end{gathered}
$$

The power equations that describe the power injection model of the UPFC are as in [7]:

$$
\begin{gathered}
P_{k m}=b_{r} V_{k} V_{m} \sin \left(\gamma+\theta_{k}-\theta_{m}\right) \\
Q_{k m}=b_{r} V_{k 2} \cos \gamma-i_{q} V_{k} \\
P_{m k}=-b_{r} V_{k} V_{m} \sin \left(\gamma+\theta_{k}-\theta_{m}\right) \\
Q_{m k}=-b_{r} V_{k} V_{m} \cos \left(\gamma+\theta_{k}-\theta_{m}\right)
\end{gathered}
$$

The POD controller can be used to modulate whatever of UPFC variables $\left(v_{p}, v_{q}, i_{q}\right)$. The set of differential equations are as follows as depicted in [7]:

$$
\begin{aligned}
& \mathrm{V}_{\mathrm{p}}=\left(\mathrm{V}_{\mathrm{po}}+\mathrm{u}_{1} \mathrm{~V}_{\text {pod }}-\mathrm{V}_{\mathrm{p}}\right) / \mathrm{T}_{\mathrm{r}} \\
& \mathrm{V}_{\mathrm{q}}=\left(\mathrm{V}_{\mathrm{qo}}+\mathrm{u}_{2} \mathrm{~V}_{\text {pod }}-\mathrm{V}_{\mathrm{q}}\right) / \mathrm{T}_{\mathrm{r}} \\
& \mathrm{I}_{\mathrm{q}}=\left[\mathrm{K}_{\mathrm{r}}\left(\mathrm{V}_{\text {ref }}+\mathrm{u}_{3} \mathrm{~V}_{\mathrm{pod}}-\mathrm{V}_{\mathrm{k}}\right)-\mathrm{i}_{\mathrm{q}}\right]
\end{aligned}
$$

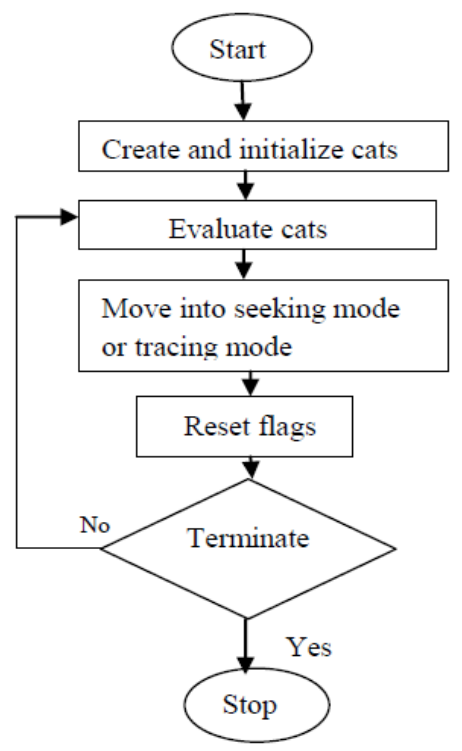

Fig 3: Flow chart for the CSO technique

Where $\mathrm{u}_{1}, \mathrm{u}_{2}$ and $\mathrm{u}_{3}$ are 1 if the correspondent stabilizing POD signal is enabled, 0 otherwise. ' $\gamma$ ' is the relative UPFC angle. $\mathrm{V}_{\mathrm{po}}$ is the initial compensation voltage. $\mathrm{V}_{\mathrm{qo}}$ is the initial compensation voltage. Where, $\mathrm{V}_{\mathrm{p}}$ represents the component of the series voltage $V_{s}$ that is in phase with the line current. In steady-state, the input $\mathrm{V}_{\mathrm{po}}$ is set to zero so that the exchange of active power between the UPFC and the ac system only takes place when this variable is modulated by the POD controller (i.e. during transients). $\mathrm{V}_{\mathrm{q}}$ represents the component of series voltage $\mathrm{V}_{\mathrm{s}}$ that is in quadrature with line current. The input $\mathrm{V}_{\mathrm{qo}}$ determines the value of the variable $\mathrm{V}_{\mathrm{q}}$ in steadystate. Two control modes are implemented for this variable:

(1) Constant voltage: the magnitude of voltage $V_{q}$ is constant independently of the line current;

(2) Constant reactance: the magnitude of the voltage $V_{q}$ varies proportionally to the line current keeping constant the total impedance of the transmission line. $I_{q}$ represents the component of shunt current $I_{\text {sh }}$ which is in quadrature with the 
bus voltage $\mathrm{V}_{\mathrm{k}}$. This current keeps the bus voltage around a specified level through the regulator gain $\mathrm{K}_{\mathrm{r}}$.

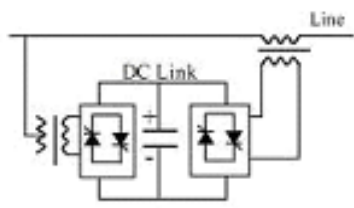

Fig 4: Structure of UPFC

\section{IMPLEMENTATION, RESULTS AND DISCUSSION}

For dynamic load modeling, Thermostatically Controlled loads are tested on IEEE 14 system and IEEE 6 bus system. Induction motor load is tested on IEEE 6 bus system. For the base case or pre disturbance case, we perform the power flow and continuation power flow and the voltages at various buses and maximum loading parameter is observed. Now the system is modeled with different types of dynamic loads and we again perform power flow and continuation power flow. The voltages at various buses and the maximum loading parameter are observed again.

By observing the results for IEEE 14 bus system which was modeled with thermostatically controlled loads, following information was obtained. As observed in table 1, thermostatically controlled loads if used, give us a stable profile of the system which implicates that, there no need to apply any stability control mechanism. The voltage magnitude profile and the maximum loadability limit of the system as observed from the PV curves in figure 5 also indicate the same. Similar kind of observation was made on for IEEE 6 bus case study too. This is shown in table 2 .

Table 1: Voltage Magnitude Profile before and after placing Thermostatically Controlled loads

\begin{tabular}{|c|c|c|}
\hline $\begin{array}{c}\text { BUS. } \\
\text { NO }\end{array}$ & $\begin{array}{c}\text { V(PU) } \\
\text { (without load) }\end{array}$ & $\begin{array}{c}\text { V(PU) } \\
\text { (with Load ) }\end{array}$ \\
\hline 01 & 1.0572 & 1.0604 \\
\hline 02 & 0.93179 & 1.0725 \\
\hline 03 & 0.85811 & 1.0537 \\
\hline 04 & 0.77903 & 1.073 \\
\hline 05 & 0.79614 & 1.0718 \\
\hline 06 & 0.82196 & 1.1465 \\
\hline 07 & 0.79451 & 1.1182 \\
\hline 08 & 0.93818 & 1.1297 \\
\hline 09 & 0.72039 & 1.1221 \\
\hline 10 & 0.71231 & 1.126 \\
\hline 11 & 0.75452 & 1.1353 \\
\hline
\end{tabular}

\begin{tabular}{|c|c|c|}
\hline 12 & 0.7663 & 1.1448 \\
\hline 13 & 0.74451 & 1.1429 \\
\hline 14 & 0.66134 & 1.1311 \\
\hline
\end{tabular}

Now the same analysis is repeated for Induction Motor loads. After incorporating the Induction Motor load on IEEE 6 bus network, the system completely blacked-out as shown in table 3. Solution for the above problem is given by UPFC using Cat Swarm Optimization heuristic approach. For optimal placement of UPFC, we first identify the weakest bus by observing the voltage magnitude profile. For installing the UPFC, the optimal size in terms of VAR ratings is determined by using Cat Swarm Optimization technique. The optimum size of the UPFC's used here in terms of its converter ratings vary from one load type to another with $50 \%$ gain and a time constant of 0.1 . The UPFC is utilized here in constant voltage mode.

Maximum values of $\mathrm{V}_{\mathrm{p}}, \mathrm{V}_{\mathrm{q}}$ and $\mathrm{I}_{\mathrm{q}}$ are $1.15,1.15$ and 1.1 in P.U. and Minimum values of $\mathrm{V}_{\mathrm{p}}, \mathrm{V}_{\mathrm{q}}$ and $\mathrm{I}_{\mathrm{q}}$ are $0.85,0.85$ and 0.9 respectively.

The parameters that constitute the dimensions of the position of the CAT in this case are listed below:

No. of Iterations carried for CSO: 50

No. of Cats used: 03

No. of Cats in seeking mode: 02

No. of Cats in Tracing Mode: 01

Amongst the three UPFC's used, two are taken in seeking mode and one is taken in tracing mode respectively and their size in terms of VAR requirement is sorted based on the number of iterations run with various number of VAR ratings induced in them based on Cat Swarm Optimization. The location is decided according to the picture obtained in table 3. 50 numbers of iteration are run for this technique, of which the global best solution is taken in to consideration.

Table 2: Voltage Magnitude Profile before and after placing Thermostatically Controlled loads

\begin{tabular}{|c|c|c|}
\hline $\begin{array}{c}\text { BUS. } \\
\text { NO }\end{array}$ & $\begin{array}{c}\text { V(PU) } \\
\text { (without } \\
\text { load) }\end{array}$ & $\begin{array}{c}\text { V(PU) } \\
\text { (with Load) }\end{array}$ \\
\hline 01 & 1.05 & 1.05 \\
\hline 02 & 1.05 & 1.05 \\
\hline 03 & 1.05 & 1.05 \\
\hline 04 & 0.53596 & 0.98592 \\
\hline 05 & 0.73347 & 0.96854 \\
\hline 06 & 0.83564 & 0.99121 \\
\hline
\end{tabular}


Table 3: Voltage Magnitude Profile before and after placing Induction Motor loads

\begin{tabular}{|c|c|c|}
\hline $\begin{array}{c}\text { BUS. } \\
\text { NO }\end{array}$ & $\begin{array}{c}\text { V(PU) } \\
\text { (without } \\
\text { load) }\end{array}$ & $\begin{array}{c}\text { V(PU) } \\
\text { (with Load })\end{array}$ \\
\hline 01 & 1.05 & 1.05 \\
\hline 02 & 1.05 & 1.05 \\
\hline 03 & 1.05 & 1.05 \\
\hline 04 & 0.53596 & 0 \\
\hline 05 & 0.73347 & 0 \\
\hline 06 & 0.83564 & 0 \\
\hline
\end{tabular}

The best location and optimal size of UPFC's for case study incorporated with Induction Machine load is between the locations 04-05, 05-03, and 03-06 with size equal to $2 \mathrm{kvar}$, $1.9 \mathrm{kvar}$, and $2 \mathrm{kvar}$. The improvement in voltage magnitude profile can be seen from table 4 . The maximum loading parameter without load was observed to be 11.1607 . This value became zero as the load was introduced. Now after incorporating the UPFC's, the value of maximum loadability increased to 8.4246 which are in par with pre-disturbance values.

The reason for choosing three UPFC devices lies in the fact that the economy in installing the devices and operating them also plays a prominent role. In present day scenario, it costs approximately 80 USD per one KVAR to operate. This approximates to 5000 INR for operation in India. UPFC has both real and reactive power components but in this paper only reactive power is considered for the reason that the load centers have a direct impact on reactive power consumption. Various load models considered here show a deficit in reactive power for which reactive power compensation is provided. Though STATCOM and SVC devices are present, we are interested in showing a solution using a sophisticated device with application of heuristic process rather than resorting to primitive solutions.

Table 4: Voltage Magnitude Profile before and after placing UPFC controllers for Induction motor load incorporated system

\begin{tabular}{|c|c|c|}
\hline $\begin{array}{c}\text { BUS. } \\
\text { NO }\end{array}$ & $\begin{array}{c}\text { V(PU) } \\
\text { (with } \\
\text { Induction } \\
\text { Motor } \\
\text { Load ) }\end{array}$ & $\begin{array}{c}\text { V(PU) } \\
\text { (with Induction } \\
\text { Motor Load } \\
\text { with UPFC's) }\end{array}$ \\
\hline 01 & 1.05 & 1.05 \\
\hline 02 & 1.05 & 1.05 \\
\hline 03 & 1.05 & 0.96724 \\
\hline 04 & 0 & 0.80547 \\
\hline
\end{tabular}

\begin{tabular}{|c|c|c|}
\hline 05 & 0 & 1.05 \\
\hline 06 & 0 & 1.05 \\
\hline
\end{tabular}

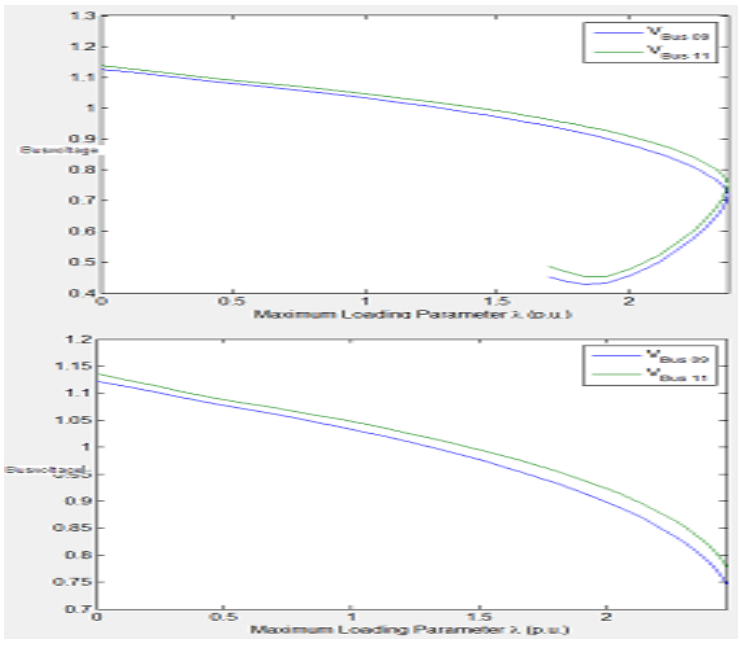

Fig 5: PV curves before and after placement of thermostatically controlled loads

\section{CONCLUSION AND FUTURE SCOPE}

The work presented in this research paper gives a load modeling study and analysis of Thermostatically Controlled and Induction Motor loads by using continuous power flow method for voltage stability analysis. The case studies considered were modeled with the two loads and checked for their performance in terms of voltage magnitude profile and maximum loading parameter. Out of the two, Thermostatically Controlled loads have shown a stable operation for a power network. Induction motors are considered critical load types for which a solution is given using UPFC. A method is also presented to determine the optimal location and size of UPFC to enhance the stability. This method is based on Cat Swarm Optimization (CSO). This algorithm was found to be easy in implementing in comparison with earlier AI techniques. It is capable of finding multiple optimal solutions to the constrained multi objective problem, giving more flexibility to make the final decision about the location and size of the FACTS controller. On conclusion, we present an advanced technique to address stability issues in large interconnected power networks, which consist of various loads. The future scope includes the testing of above techniques for high end IEEE case studies and practical networks.

\section{REFERENCES}

[1] C W Taylor, Power System Voltage Stability, New York, McGraw-Hill, 1994.

[2] Prabha Kundur, Neal J Balu, Mark G Lauby, Power Systems Dynamics and Stability, McGraw-Hill, 01-Jan1994.

[3] Hingorani N G, Gyugyi L, "Understanding FACTS: Concepts and Technology of Flexible AC Transmission Systems", IEEE Press, New York, 2000.

[4] John J Paserba, "How FACTS Controllers Benefit AC Transmission Systems", Transmission and Distribution Conference and Exposition, 2010, IEEE PES, New Orleans, LA, USA. 
[5] "Proposed Terms and Definitions for Flexible AC Transmission System (FACTS)", IEEE Transactions on Power Delivery, Volume 12, 1997.

[6] F Milano, "Power System Analysis Toolbox", Version 1.3.4, Software and Documentation, July 14, 2005.

[7] Power System Analysis Toolbox Documentation for PSAT version 2.0.0 $\beta$, March 8, 2007.

[8] A Kazemi, V Vahidinasab, A Mosallanejad, "Study of STATCOM and UPFC Controllers for Voltage Stability Evaluated by Saddle-Node Bifurcation Analysis", First International Power and Energy Conference, November 28-29, 2006, Putrajaya, Malaysia.

[9] Musunuri S, Dehnavi G, "Comparison of STATCOM, SVC, TCSC, and SSSC performance in Steady State Voltage Stability Improvement", North American Power Symposium (NAPS), 26-28 Sept. 2010, pp $1-7$.

[10] Kalaiselvan G, Lavanya A, Natrajan V, "Enhancing the Performance of Watermarking based on Cat Swarm Optimization Method", IEEE International Conference on Recent Trends in Information Technology, Anna University, Chennai, June 3-5, 2011.

[11] Jong Ching Hwang, Jung Chin Chen, J S Pan, Yi Chao Huang, "CSO and PSO to Solve Optimal Contract Capacity for High Tension Customers", IEEE, PEDS, 2009.
[12] Budi Santosa, Mirsa Kencana Ningrum, "Cat Swarm Optimization for Clustering", International Conference on Soft Computing and Pattern Recognition, 2009.

[13] Wen Zing, Adeline Chan, "Power System Load Modeling", The School of Information Technology and Electrical Engineering, University of Queensland, October 2003.

[14] Cheng Hong Gu, Qian Ai, Jiayi Wu, "A Study of Effect of Different Static Load Models and System Operating Constraints on Static Voltage Stability", Proceedings of the 5th WSEAS/IASME International Conference on Systems Theory and Scientific Computation, Malta, September 15-17, 2005 pp 44-49.

[15] Shu-Chuan Chu, Pei-Wei Tsai and Jeng-Shyang Pan, "Cat Swarm Optimization", 9th Pacific Rim International Conference on Artificial Intelligence, LNAI 4099, pages 854-858, 2006.

[16] Pei-Wei Tsai, Jeng-Shyang Pan, Shyi-Ming Chen and Bin-Yih Liao, "Enhance Parallel Cat Swarm Optimization method based on the Taguchi Method", Expert Systems with Applications, Volume 39, Issue 7, pages 6309-6319, 2012.

[17] Chia-Jen, Yung-Tien Chen, "Dynamic Load Models in Power Systems using the Measurement Approach", IEEE Transactions on Power Systems, Volume 8, Issue 1, pp 309-315, February 1993. 